\title{
The Effect of Changing Substrate Material and Thickness on the Performance of Inset Feed Microstrip Patch Antenna
}

\author{
Liton Chandra Paul' ${ }^{1}$, Md. Sarwar Hosain ${ }^{2}$, Sohag Sarker², Makhluk Hossain Prio ${ }^{3}$, \\ Monir Morshed ${ }^{4}$, Ajay Krishno Sarkar ${ }^{3}$ \\ ${ }^{1}$ Department of Electronic and Telecommunication Engineering, Pabna University of Science \& Technology, Pabna, Bangladesh \\ ${ }^{2}$ Department of Information and Communication Engineering, Pabna University of Science \& Technology, Pabna, Bangladesh \\ ${ }^{3}$ Department of Electrical and Electronic Engineering, Rajshahi University of Engineering \& Technology, Rajshahi, Bangladesh \\ ${ }^{4}$ Department of Information and Communication Technology, Mawlana Bhashani Science and Technology University,Tangail, Bangladesh
}

\section{Email address:}

litonpaulete@gmail.com (L. C. Paul), sarwar.iceru@gmail.com (M. S.Hosain), sohagsarker5614@gmail.com (S.Sarker), makhlukpr158@gmail.com (M. H.Prio),monirmorshed.mbstu@gmail.com (M.Morshed), sarkarajay139@gmail.com (A. K. Sarkar)

\section{To cite this article:}

Liton Chandra Paul, Md. Sarwar Hosain, Sohag Sarker, Makhluk Hossain Prio, Monir Morshed, Ajay Krishno Sarkar. The Effect of Changing Substrate Material and Thickness on the Performance of Inset Feed Microstrip Patch Antenna. American Journal of Networks and Communications. Vol. 4, No. 3, 2015, pp. 54-58.doi: 10.11648/j.ajnc.20150403.16

\begin{abstract}
In order to design a microstrip patch antenna at first the designer is to select the substrate material and it's thickness. So, if the designer has a clear conception about the effect of changing substrate material and it's thickness on the performance of the antenna, it will be easier to design an antenna. Appropriate selection of dielectric material and it's thickness is an important task for designing a microstrip patch antenna. This paper represents that how antenna performance changes when we vary substrate material and it's thickness. The designed inset feed rectangular microstrip patch antenna operates at $2.4 \mathrm{GHz}$ (ISM band).
\end{abstract}

Keywords: Inset Feed, Dielectric Constant, Substrate Thickness, Bandwidth, Return Loss, Gain, Directivity, Radiation Efficiency

\section{Introduction}

Microstrip patch antennas consist of a metallic patch on a grounded substrate.The microstrip patch antenna first took form in the early 1970's and interest was renewed in the first microstrip antenna proposed by Deschamps in 1953[1]. Microstrip antennas have found widespread applications for microwave as well as millimeter wave systems [2].Compatible devices are widely used in our daily lives such as mobile phones, laptops with wireless connection, wireless universal serial bus (USB) dongles etc and microstrip patch antenna plays a very significant role for the miniaturization of these devices [3]. The applications in present-day mobile communication systems usually require smaller antenna size in order to meet the miniaturization requirements of mobile units. Thus, size reduction and bandwidth enhancement are becoming major design considerations for practical applications of microstrip antennas. The microstrip patch antennas are well known for their performance and their robust design, fabrication and their extent usage. The inherently narrow impedance bandwidth is the major weakness of a microstrip antenna [4]. Although we used rectangular shaped patch but the radiating patch can be of any geometrical configuration like square, rectangle, circular, elliptical, triangular, E-shaped, H-shaped, L-shaped, U shaped etc. The material which has the dielectric constant in the range of $2.2 \leq \varepsilon_{\mathrm{r}} \leq 12$ can be used as substrate [5]. When we change the substrate material and the thickness of substrate of a microstrip antenna, it changes the system performance. Therefore, in order to introduce appropriate correctness in the design of the antenna, it is important to know the effect of changing dielectric substrate material and substrate thickness. A set of simulation and measurements of inset feed rectangular patch antenna on different substrate material (RT Duroid 5880, GML 1000, RO4003 and FR-4) and on the same substrate material by varying substrate thickness is presented in this research paper. The design, simulation and measurements are performed by advanced design system (ADS) 2009 momentum. 


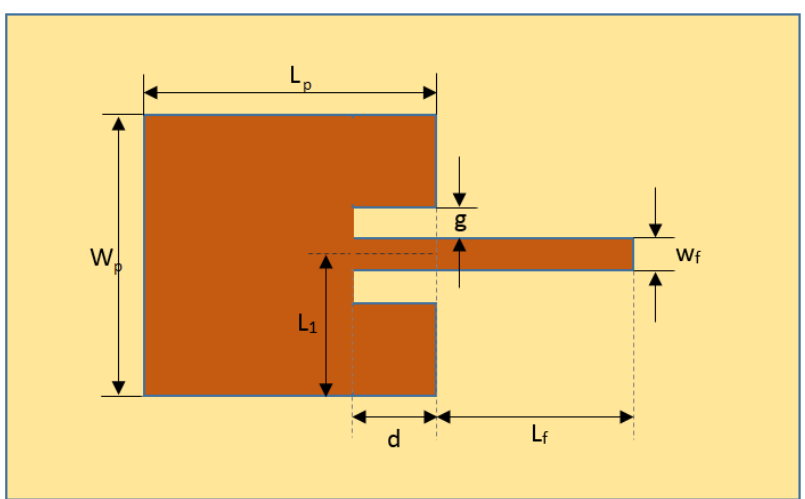

Fig. 1. Inset feed rectangular microstrip patch antenna layout.

\section{Feeding Technique}

A feedline is used to excite the antenna for making radiation by direct or indirect contact. Microstrip patch antennas can be fed by a variety of methods. Mainly these methods are classified into two groups- contacting and noncontacting. Some popular feeding techniques are microstrip line feed, coaxial probe feed, inset feed/ notch feed/cut feed, aperture coupling, proximity coupling, coupled (indirect) fed etc. The selection of feeding technique for a microstrip patch antenna is an important decision because it directly affects the bandwidth, return loss, VSWR, patch size and smith chart [6]. We chose Inset feed technique because it can be easily fabricated and simplicity in modeling as well as impedance matching [7]. The fig.1 shows the layout of inset feed rectangular microstrip patch antenna with required dimensions. Where, $\mathrm{W}_{\mathrm{p}}=$ width of patch, $\mathrm{L}_{\mathrm{p}}=$ Length of patch, $\mathrm{W}_{\mathrm{f}}=$ Width of feeder, $\mathrm{L}_{\mathrm{f}}=$ Length of feeder, $\mathrm{d}=$ inset depth, $\mathrm{g}$ $=$ notch width $/$ inset width/gap width and $\mathrm{L}_{1}=$ position of feeder from the left edge of the patch.

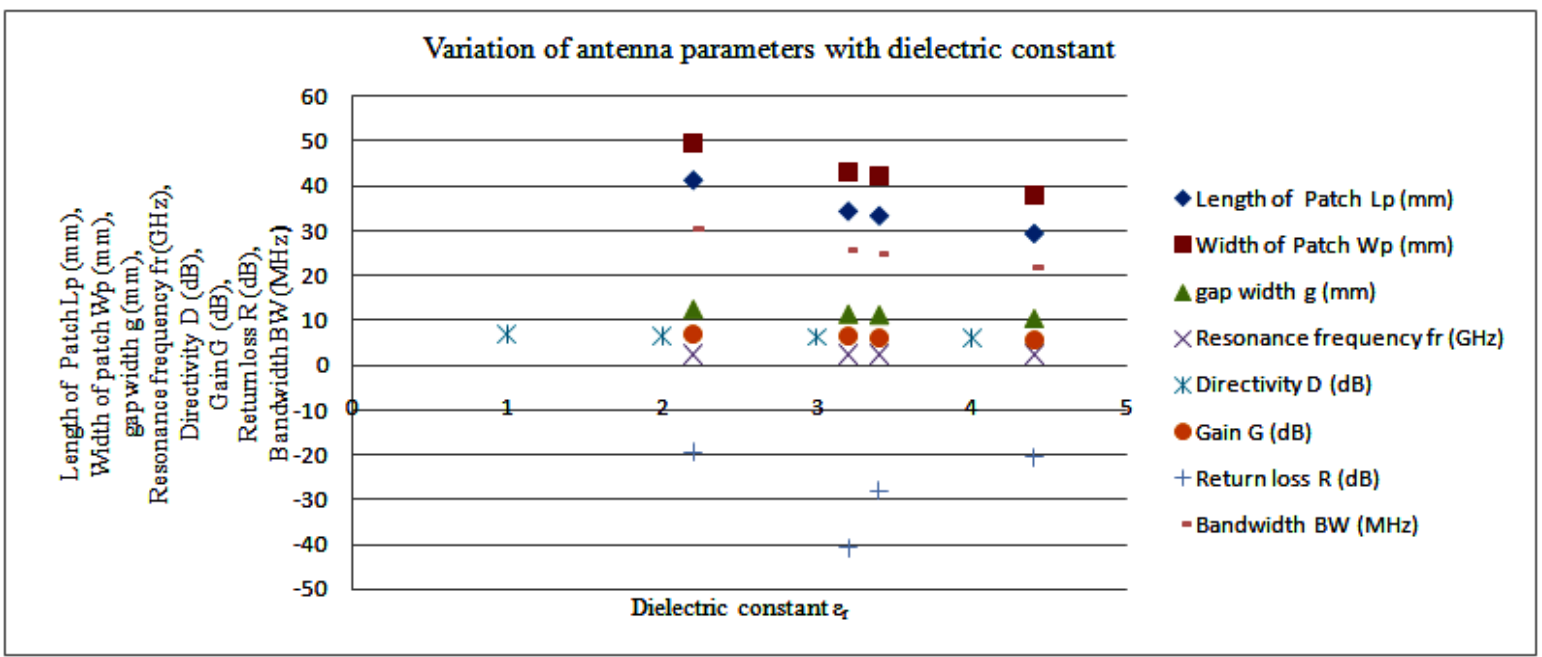

Fig. 2. Variation of antenna parameters with substrate material.

\section{Design of Rectangular Microstrip Patch Antenna}

In the typical design procedure of rectangular Microstrip patch antenna, three essential parameters are [8]:

1. Resonance frequency $f_{r}$

2. Dielectric constant of the substrate, $\varepsilon_{\mathrm{r}}$

3. Thickness of substrate, $h$

After the proper selection of above three parameters, the next step is to calculate the radiating patch width and length.The designing procedure can be divided following steps:

Step 1: Calculation of width of patch $\left(\mathrm{W}_{\mathrm{p}}\right)$

For an efficient radiator, practical width that leads to good radiation efficiencies is [9]

$$
W_{P}=\frac{c}{2 f_{r}} \sqrt{\frac{2}{\varepsilon_{r}+1}}
$$

Where, $\mathrm{c}=$ velocity of light $=3 \times 10^{8} \mathrm{~m} / \mathrm{s}$ $\mathrm{f}_{\mathrm{r}}=$ resonance frequency

$\varepsilon_{\mathrm{r}}=$ dielectric constant

Step 2: Calculation of effective dielectric constant,

$$
\varepsilon_{r}^{e f f}=\frac{\varepsilon_{r}+1}{2}+\frac{\varepsilon_{r}-1}{2}\left[\frac{1}{\sqrt{1+\frac{12 h}{w_{p}}}}\right]
$$

Step 3: Calculation of effective length of patch,

$$
L_{e f f}=\frac{c}{2 f_{r} \sqrt{\varepsilon_{r}^{e f f}}}
$$

Step 4: Calculation of length extension,

$$
\Delta L=0.412 h \frac{\left(\varepsilon_{r}^{e f f}+0.3\right)\left(\frac{W_{p}}{h}+0.264\right)}{\left(\varepsilon_{r}^{e f f}-0.258\right)\left(\frac{W_{p}}{h}+0.8\right)}
$$

Step 5: Calculation of actual length of patch,

$$
L_{p}=L_{\text {eff }}-2 \Delta L
$$


Step 6: calculation of inset depth

$$
Z_{o}=Z_{i n} \cos ^{2}\left(\frac{\pi d}{L_{p}}\right)
$$

Where,

$\mathrm{Z}_{\mathrm{o}}=$ Characteristics impedance

$\mathrm{Z}_{\text {in }}=$ input impedance

$\mathrm{d}=$ inset depth/notch depth/gap depth

Table I. Variation of antenna parameters with different substrate material.

\begin{tabular}{|c|c|c|c|c|c|c|c|c|c|}
\hline $\begin{array}{l}\text { Substrate } \\
\text { Material } \\
\text { Name } \\
\end{array}$ & $\begin{array}{l}\text { Dielectric } \\
\text { constant } \\
\varepsilon_{\mathrm{r}} \\
\end{array}$ & $\begin{array}{l}\text { Length } \\
\text { of Patch } \\
\mathrm{L}_{\mathrm{p}}(\mathrm{mm}) \\
\end{array}$ & $\begin{array}{l}\text { Width of } \\
\text { PatchW } \\
(\mathrm{mm})\end{array}$ & $\begin{array}{l}\text { Inset } \\
\text { depthd(mm) }\end{array}$ & $\begin{array}{l}\text { Resonance } \\
\text { frequencyf }_{\mathrm{r}} \\
(\mathrm{GHz})\end{array}$ & $\begin{array}{l}\text { Directivity D } \\
\text { (dB) }\end{array}$ & $\begin{array}{l}\text { GainG(dB } \\
\text { ) }\end{array}$ & $\begin{array}{l}\text { Return } \\
\text { lossR(dB) }\end{array}$ & $\begin{array}{l}\text { Bandwidth } \\
\text { BW(MHz) }\end{array}$ \\
\hline $\begin{array}{l}\text { RT Duroid } \\
5880\end{array}$ & 2.2 & 41.408 & 49.410 & 12.398 & 2.406 & 7.00870 & 7.00410 & -19.402 & 30.5 \\
\hline GML 1000 & 3.2 & 34.483 & 43.129 & 11.312 & 2.411 & 6.38395 & 6.37818 & -41.363 & 26 \\
\hline RO4003 & 3.4 & 33.472 & 42.137 & 11.126 & 2.408 & 6.30076 & 6.29490 & -27.994 & 25 \\
\hline FR-4 & 4.4 & 29.479 & 38.036 & 10.321 & 2.408 & 5.98928 & 5.68109 & -20.516 & 22 \\
\hline
\end{tabular}

\section{Effect of Changing Substrate Material}

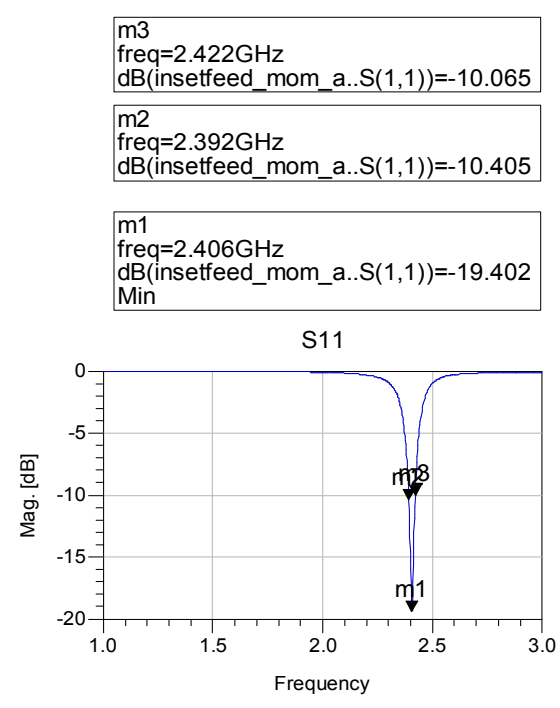

Fig. 3. $\mid$ S11 $\mid$ for RT Duroid 5880.
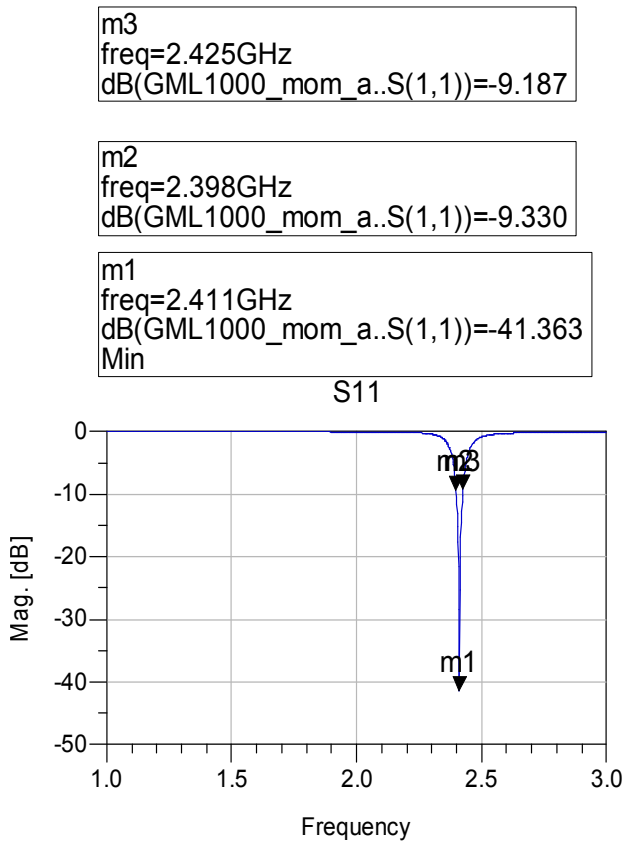

Fig. 4. $\mid$ S11 for GML 1000.

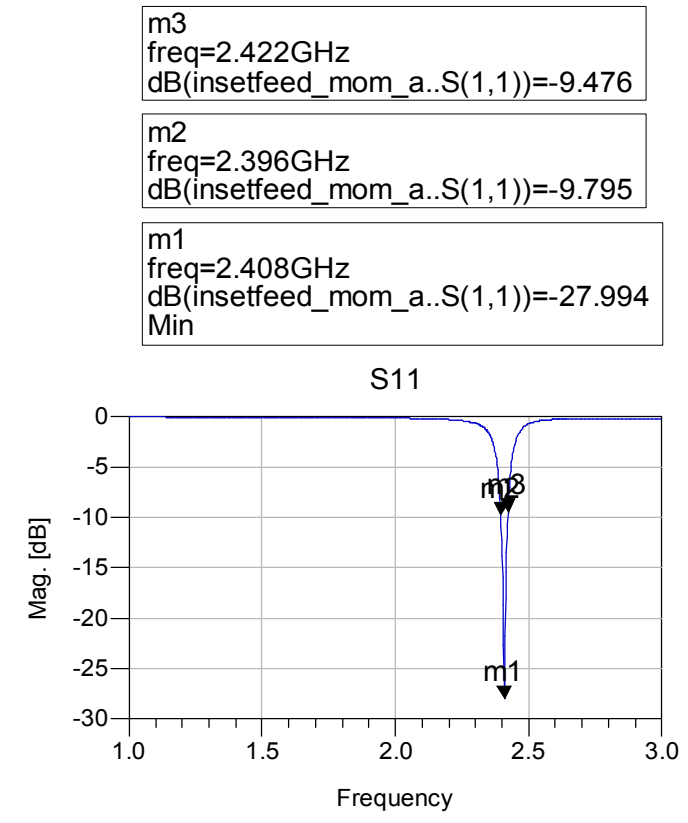

Fig. 5. $|S 11|$ for RO4003.

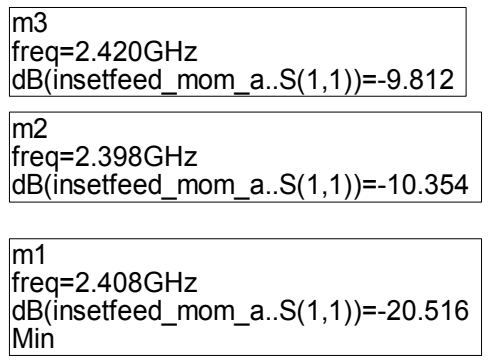

S11

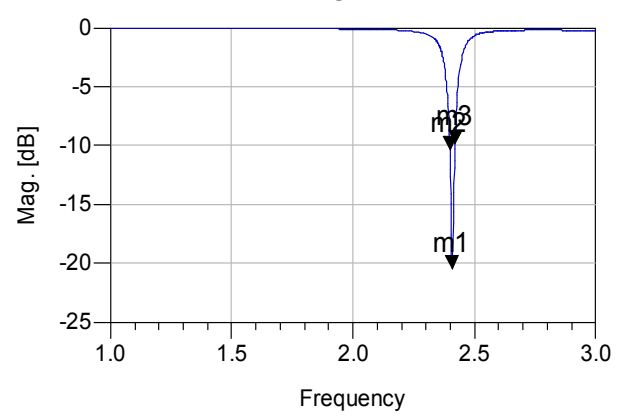

Fig. 6. $|S 11|$ for FR-4. 
With changing the substrate material, the dielectric constant of the substrate changes i.e. changing the substrate material means the changing the dielectric constant $\left(\varepsilon_{\mathrm{r}}\right)$. Although, wide variety of substrate materials have been found to exist suitable for microstrip patch antenna design with mechanical, thermal, and electrical properties which are attractive for use in both planar and conformal antenna configurations. However tolerance control of the dielectric constant remains a problem for accurate designs, particularly at higher microwave and millimeter frequencies [10]. Here, we used four different substrate materials - RT Duroid 5880, GML 1000, RO4003 and RF-4 whose dielectric constants are $2.2,3.2,3.4$ and 4.4 respectively for the same antenna configuration $\left(\mathrm{f}_{\mathrm{r}}=2.4 \mathrm{GHz}, \mathrm{g}=1.5 \mathrm{~mm}, \mathrm{~h}=1.5 \mathrm{~mm}, \mathrm{t}=0.1 \mathrm{~mm}\right.$, $\left.\mathrm{L}_{\mathrm{f}}=31.25 \mathrm{~mm} \quad \& \mathrm{~W}_{\mathrm{f}}=4 \mathrm{~mm}\right)$. For every different substrate material we determined the antenna performance parameters like resonance frequency, directivity, gain, return loss, bandwidth as well as the dimension of patch of the antenna (length of patch, width of patch and inset depth). These antennas are designed and simulated by using advanced design system (ADS) 2009 momentum simulator. Table I shows the antenna parameters variation summary with changing substrate material. From the data table I, it is clear that, by using substrate material with higher dielectric constant $\left(\varepsilon_{\mathrm{r}}\right)$, the length of patch $\left(\mathrm{L}_{\mathrm{p}}\right)$, width of patch $\left(\mathrm{w}_{\mathrm{p}}\right)$, inset depth (d), Directivity (D), Gain (G), Bandwidth (BW) decreases. There are also significant changes of return loss (R). The fig. 2 shows the graphical representations of the data are listed in table I with respected to dielectric constant of the substrate material.

Table II. Variation of antenna parameters with substrate thickness.

\begin{tabular}{|c|c|c|c|c|c|c|c|}
\hline $\begin{array}{l}\text { h } \\
(\mathrm{mm})\end{array}$ & $\begin{array}{l}\mathbf{L}_{\mathbf{p}} \\
(\mathrm{mm})\end{array}$ & $\begin{array}{l}d \\
(\mathrm{~mm})\end{array}$ & $\begin{array}{l}\mathbf{f}_{\mathbf{r}} \\
(\mathrm{GHz})\end{array}$ & $\begin{array}{l}\text { D } \\
(\mathrm{dB})\end{array}$ & $\begin{array}{l}\text { G } \\
(d B)\end{array}$ & $\begin{array}{l}\text { R } \\
\text { (dB) }\end{array}$ & $\begin{array}{l}\text { BW } \\
\text { (MHz) }\end{array}$ \\
\hline 0.5 & 41.932 & 12.555 & 2.421 & 6.88037 & 2.62412 & -0.836 & \\
\hline 1.3 & 41.522 & 12.432 & 2.398 & 6.91738 & 2.76126 & -1.651 & \\
\hline 1.5 & 41.408 & 12.398 & 2.410 & 7.00735 & 7.00274 & -27.221 & 31.5 \\
\hline 2.5 & 40.784 & 12.212 & 2.394 & 7.03605 & 7.03202 & -19.637 & 56 \\
\hline 3 & 40.448 & 12.110 & 2.384 & 7.04630 & 7.02344 & -20.059 & 68 \\
\hline 3.5 & 40.099 & 12.006 & 2.372 & 7.06027 & 7.00487 & -22.496 & 81 \\
\hline 4 & 39.741 & 11.899 & 2.362 & 7.07394 & 6.98569 & -28.280 & 91 \\
\hline 4.5 & 39.374 & 11.789 & 2.354 & 7.08734 & 6.96575 & -39.232 & 99 \\
\hline
\end{tabular}

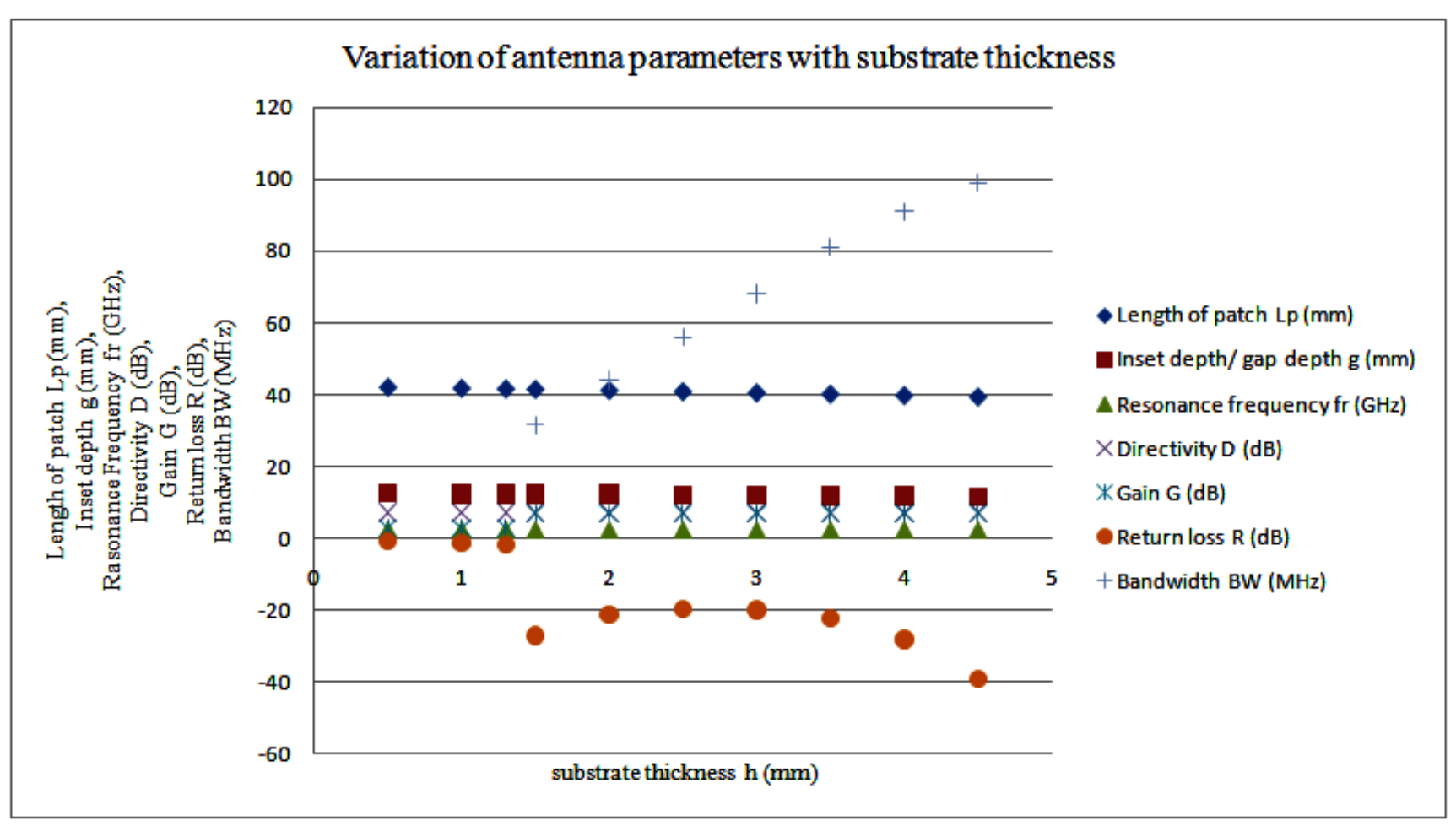

Fig. 7. Variation of antenna parameters with substrate thickness. 


\section{Effect of Substrate Thickness Variation}

Selection of proper substrate thickness is another important task in microstrip patch antenna design. To choose appropriate substrate thickness (h), a designer needs to know the effect of changing substrate thickness. Here, we measure the antenna parameters by varying substrate thickness (h) from $0.5 \mathrm{~mm}$ to $4.5 \mathrm{~mm}$ for an inset feed rectangular microstrip patch antenna. The measured data are listed in table II. RT Duroid 5880 substrate with dielectric constant $\varepsilon_{\mathrm{r}}=2.2$ used for this analysis.

From the data table II, it is seen that with increasing the substrate thickness, the bandwidth increases but the antenna dimension decreases as well as the center operating frequency move away from the desired resonance frequency (for this design $2.4 \mathrm{GHz}$ ). Fig.7. shows the graphical representation of the antenna parameters which are given in table II with respect to substrate thickness (h).

\section{Conclusion}

From the above analysis, we can conclude that the use of substrate material with higher dielectric constant in microstrip patch antenna design, results degradation of antenna performance but size of the antenna reduces. With increasing substrate thickness $(\mathrm{h})$, the resonance frequency decreases but the bandwidth increases. The performance of the antennas was measured for $2.4 \mathrm{GHz}$ operating frequency using inset feeding technique with advanced design system (ADS) 2009 momentum 3D planar electromagnetic simulator.

\section{References}

[1] S. S. Holland "Miniaturization of microstrip patch antennas for GPD Applications", M.Sc. thesis, Dept. of Electrical And Computer Engineering,University of Massachusetts Amherst,May 2008.

[2] W. Menzel and W. Grabherr,"A Microstrip Patch Antenna with CoplanarFeed Line",IEEE microwave and guided wave letters, Vol. 1,No. 11,November 1991.

[3] Deepak, D. Parashar, R. S. Pathak and S. K. Bhartiya. "Effect of Change in Feed point on the Micro strip Patch Antenna Performance in Novel H shape Antenna", International Journal of Emerging Trends in Engineering and Development,
Vol.5, Issue 3, September 2013.

[4] C. L. Mak, K. M. Luk, K. F. Lee and Y. L. Chow , "Experimental Study of a Microstrip Patch Antenna with an L-Shaped Probe",IEEE Transactions on antennas and propagation, vol. 48, no. 5, May 2000

[5] S. A. Zaidi and M.R. Tripathy "Design and Simulation Based Study of Microstrip E-Shaped Patch Antenna Using Different Substrate materials ",Advance in Electronic and Electric Engineering., Volume 4, Number 6, pp 611, 2014

[6] K. P. Kumar, K. S.Rao, T. Sumanth, N. M.Rao, R. A. Kumar andY.Harish,"Effect of feeding techniques on the radiationcharacteristics of patch antenna design and analysis", International Journal of Advanced Research in Computer and Communication Engineering, Vol. 2, Issue 2, February 2013.

[7] A. I. Salem, A. A. Salama, A. M. Eid, M. Sobhy, and A. watany, "Performance Enhancement of Fabricated and Simulated Inset Fed Microstrip Rectangular Patch Antennas", International Journal of Scientific \& Engineering Research, Volume 5, Issue 4, April 2014.

[8] T. k. Raina "Design, fabrication and performance Evaluation of micro-strip patch Antennas for wireless applications", M.Sc thesis, Department of Electronics and Communication Engineering, Thapar University, Patiala, June 2012.

[9] Using aperture coupled feedh. Singh, Y.K.Awasthi and A.K.Verma "Microstrip Patch Antenna with the Defected Ground Structure and Defected Microstrip Structure" proceedings of International Confrence on Microwave, 2008.

[10] Keith R. Carver, and James W. Mink, "Microstrip antenna technology", IEEE transactions on antennas and propagation", Vol AP-29, no.1,pp 21,January 1981.

[11] J. W. Salman, M.M. Ameen and S. O. Hassan "Effects of the Loss Tangent, Dielectric Substrate Permittivity and Thickness on the Performance of Circular Microstrip Antennas"Journal of Engineering and Development, Vol. 10, No.1, March 2006.

[12] K.P. Kumar, K.S. Rao, V. M. Rao, K. Uma, A. Somasekhar and C. M. Mohan "The effect of dielectric permittivity on radiation characteristics of co-axially feed rectangular patch antenna: Design \& Analysis",International Journal of Advanced Research in Computer and Communication Engineering, Vol. 2, Issue 2, February 2013.

[13] V. Natarajan and C. Chatterjee, "Effect of substrate permivity and thickness on performance on single layer, wideband, Uslot antennas on microwave substrates", $20^{\text {th }}$ annual review of progress in applied computational Electromagnetics, April 2004. 